\title{
DEVELOPING A KNOWLEDGE MANAGEMENT SYSTEM FOR INTEGRATED VEHICLE HEALTH MANAGEMENT USING A DATA LIFE CYCLE MODEL.
}

\author{
Alexslis Maindze
}

\author{
Cranfield University, Integrated Vehicle Health Management Centre, College Road, Cranfield, Bedfordshire MK43 \\ OAL, United Kingdom \\ alexslis.maindze@cranfield.ac.uk
}

\begin{abstract}
Data forms the foundation on which knowledge is created, captured, used and shared. The lack of an approach consistent with technological changes and needs can facilitate loss of knowledge and increased costs. Integrated Vehicle Health Management (IVHM) is characterized by prognostics and diagnostics which depend heavily on high quality data to perform datadriven, model-based and hybrid computational analysis of asset health. As a result, managing data and knowledge for Integrated Vehicle Health Management (IVHM) requires a data life cycle model that adopts the OSA-CBM data model and integrate with other approaches. This project will propose such a model and use it to support the development of an IVHM knowledge management system*.
\end{abstract}

\section{PROBLEM STATEMENT}

Knowledge management over the years has become a central foundation for business improvement, sustainability and competitiveness. This occurred against the back drop of organizations seeking to manage their hard and soft assets better through greater integration with information technologies. A specific area in which the management of data, information and knowledge is fundamental for its success, is the field of Integrated Vehicle Health Management (IVHM). IVHM is shaped by prognostics and diagnostics that rely predominantly on the availability of high quality data to perform data-driven, model-based and hybrid computational analysis of asset health. The data has to be accurate, complete, timely, context relevant, reliable and explicit (Dibsdale, 2011).

The IVHM Centre at Cranfield University has existed since 2008 and runs an active research program that generates high value knowledge through theoretical and experimental work. The Centre produces a wide range

\footnotetext{
* Alexslis Maindze. This is an open-access article distributed under the terms of the Creative Commons Attribution 3.0 United States License, which permits unrestricted use, distribution, and reproduction in any medium, provided the original author and source are credited.
}

of algorithms and processes to capture and analyze data from experiments carried out on rigs and other facilities. The Centre has worked on more than 40 projects, generating more than 120 technical papers, publishing 6 books, and generating lots of algorithms and experimental data, from 10 experimental rigs (Skaf and Jennions, 2017). With this growth in the creation of research data, data automating algorithms, technical papers, reports and theses, the Centre needs both a data management model and a knowledge management system that facilitate the storing, organizing and sharing of its research outputs and which is secure and scalable with a high level of cross platform transferability.

However, the IVHM Centre does not yet have a systematic and coherent approach to IVHM knowledge and data management. The absence of a data life cycle model and knowledge management system means that valuable knowledge is lost or is very difficult to find. Data visualization is fragmented and done on a project by project basis which increases costs. There is insufficient algorithm documentation and communication for easy transition between subsequent researchers and personnel. A knowledge management system is therefore needed to improve the short and long-term transferability of the Centre's range of research projects and the outputs from these projects. A system that presents information to enable browsing by a range of categories and searching on specific terms is desired.

\section{EXPECTED CONTRIBUTIONS}

The main contribution of the research will consist in the development of an integrated data life cycle model that uniquely addresses the challenges of managing experimental data, algorithms, research reports, storage and dissemination in the context of IVHM. The research proposes a data life cycle model for IVHM based on an integration and enhancement of best data models: the USGS data management life cycle model (Faundeen and Hutchison, 2017), and the core scientific metadata model (Yang, Matthews and Wilson, 2013), with the OSA-CBM (MIMOSA, 2018) framework. 
Annual Conference of the Prognostics and Health Management Society, 2012

Moreover, the research enriches the debate on data management challenges and related frameworks.

\section{RESEARCH PLAN}

The research project is planned to be completed within the scheduled 36 months starting February 2017. The first year of the study has been completed. It is likely that some tasks will be performed in parallel.

\begin{tabular}{|c|c|}
\hline TASK & DURATION \\
\hline Systematic Literature Review & 7 months \\
\hline Reports & 2 months \\
\hline Conference/ Journal Articles & 3 months \\
\hline Requirements Definition & 1 months \\
\hline $\begin{array}{l}\text { Develop IVHM Data Life Cycle } \\
\text { Model }\end{array}$ & 1 months \\
\hline $\begin{array}{l}\text { Design IVHM Knowledge } \\
\text { Management System }\end{array}$ & 2 months \\
\hline Implement/Deploy KM System & 7 months \\
\hline Test and Validate KMS \& Model & 5 months \\
\hline Write up thesis & 8 months \\
\hline Total & 36 Months \\
\hline
\end{tabular}

Table 1: Research project plan

In addition to the main research, estimates for writing conference and journal articles and progress reports have been included.

\subsection{Work Performed}

The review of the literature highlighted, first of all, the need to understand the concept of knowledge management at a fundamental level. A detailed literature review that studies Data life cycle models, frameworks, standards and process models pertaining to knowledge management in the context of IVHM has been performed.

The literature review began with a scoping study and exploration of the concept of knowledge management and what it means in the context of this study. No universally accepted definition of knowledge management exists, which is indicative of an "Intellectual paradox" (Maindze, Jennions and Skaf, 2017) and an operational definition was proposed to address this situation:

"Knowledge management is a multidisciplinary science and process of organizational knowledge creation and retention that engages people, process, environment and technology to create, retain or increase value" (Maindze, Jennions, and Skaf 2017:525).
Furthermore, taking a theoretically informed perspective on the challenges discussed in section one above, IVHM can be described as a data-centric activity which is driven by the Open System Architecture for Condition-Based Maintenance (OSACBM) data model. OSA-CBM is a standard architecture for moving information in a conditionbased maintenance system developed by the US Navy through a Dual Use Science and Technology (DUST) program and administered by MIMOSA - a non-profit 501(c)6 industry association, focused on allowing industry solutions leveraging dealer independent, open standards, to create an interoperable industrial ecosystem for the Commercial off-the-Shelf (COTS) solutions components provided by major industry dealers.

The centrality of data for IVHM in the short, medium and long-term, whether it be historical asset health trends, operational status, load history, or fault identification, necessitates a data life cycle model or a hybrid model consistent with OSA-CBM. Of all the existing data life cycle models, there is none that adopts the IVHM data model and meets the IVHM knowledge management requirements. The OSA-CBM model is based on the concept of metadata and interoperability that requires persistent visibility and traceability of data (Choudhary, Perinpanayagam and Butans, 2016) within and across diverse platforms, systems and devices, and therefore making data provenance a fundamental requirement.

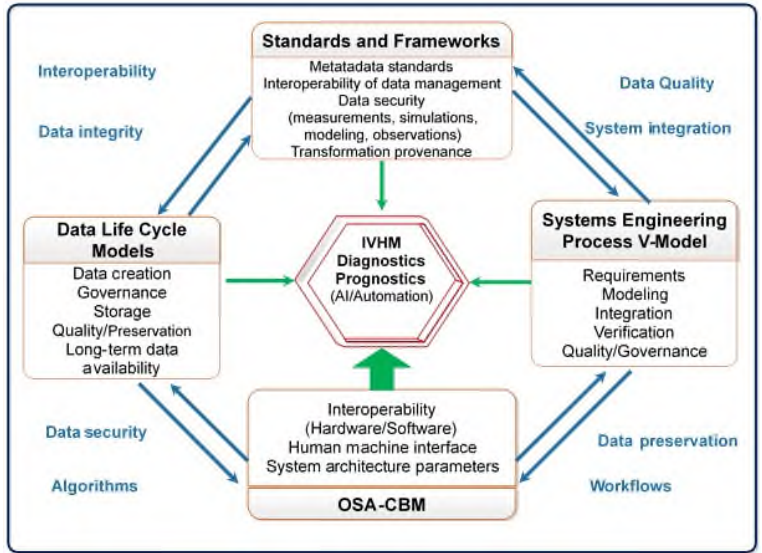

Figure 1: Data and knowledge management conceptual model

Figure 1 expresses the conceptual relationship between key concepts and aspects of the practice of IVHM. The conceptual model above sheds light on the relationship between standards, data life cycle models, OSA-CBM and the International Council on Systems Engineering (INCOSE) systems engineering process model. The INCOSE Systems Engineering process or Vee Model is a process for ensuring the effective and 
efficient, high quality, trust-worthy, cost efficient stakeholder requirements throughout a systems life cycle. The Vee Model life cycle is a waterfall-like stepby-step process implementation that ensures predictability, stability, reproducibility and security. A key strength of the systems engineering process is the consideration of the complete life cycle of a project during the project development phase.

\subsection{Remaining Work}

At the moment, I am working on the Data Life Cycle Model and the Design for the IVHM Knowledge Management System based on SharePoint 2016. These tasks are expected to be complete by the $16^{\text {th }}$ of May 2018 and the $15^{\text {th }}$ of June 2018 respectively. Table 2 below shows the main remaining tasks to the end of the project.

\begin{tabular}{|c|c|}
\hline TASK & DURATION \\
\hline Articles, Updates, Reports & 2.5 Months \\
\hline $\begin{array}{l}\text { Develop IVHM Data Life Cycle } \\
\text { Model }\end{array}$ & 1 months \\
\hline $\begin{array}{l}\text { Design IVHM Knowledge } \\
\text { Management System }\end{array}$ & 1.5 months \\
\hline Implement/Deploy KM System & 7 months \\
\hline Test and Validate KMS \& Model & 5 months \\
\hline Write up thesis & 7 months \\
\hline Tot & 24 Months \\
\hline
\end{tabular}

Table 2: Research Project Remaining Tasks

\section{CONCLUSION}

Of all the existing data life cycle models, there is none that is consistent with the requirements of IVHM data and knowledge management requirements that integrates the OSA-CBM framework which is imperative to IVHM. IVHM capability includes prognostics and diagnostics which rely predominantly on the availability of high quality data to perform datadriven, model-based and hybrid computational analysis of asset health. The data has to be accurate, complete, timely, context relevant, reliable and explicit (Dibsdale, 2011). IVHM is data-centric and driven by the OSACBM data model. The centrality of data for IVHM in the short, medium and long-term diagnostics whether it be historical asset health trends, operational status, load history, or fault identification, necessitates a data life cycle model or a hybrid model consistent with the OSA-CBM framework. The OSA-CBM framework is based on the concept of metadata and interoperability that requires persistent visibility and traceability of data (Choudhary, Perinpanayagam and Butans, 2016) within and across diverse platforms, systems and devices, and therefore makes data provenance a fundamental requirement. This has not been explicitly covered in any of the data life cycle models. A new model is needed and one that integrates data acquisition with signal reception as well as data entry in order to accommodate the role of the systems or device operators for IVHM. The new model will integrate USGS Data Life Cycle Model, with OSA-CBM Framework and the Core Scientific Metadata Model.

\section{REFERENCES}

Choudhary, R., Perinpanayagam, S. and Butans, E. (2016) 'Design and Analysis of Communication Model for Implementation of CBM Systems Based on OSA-CBM Framework', in 2016 IEEE Aerospace Conference, pp. 1-7. doi: 10.1109/AERO.2016.7500821.

Dibsdale, C. (2011) 'Integrated Vehicle Health Management Operations Rooms', in Jennions, I. K. (ed.) Integrated Vehicle Health Management: Perspectives on an Emerging Field. SAE International, pp. 113-123.

Faundeen, J. and Hutchison, V. (2017) 'The Evolution, Approval and Implementation of the U.S. Geological Survey Science Data Lifecycle Model', Journal of eScience Librarianship, 6(2), p. e1117. doi: 10.7191/jeslib.2017.1117.

Maindze, A., Jennions, I. and Skaf, Z. (2017) 'Knowledge Management Yesterday and Tomorrow: Exploring an "intellectual paradox", in James Gao, Mohammed El Souri, S. K. (ed.) Advances in Transdisciplinary Engineering. Amsterdam: IOS Press, pp. 522-527. doi: 10.3233/978-1-61499-792-4-522.

MIMOSA (2018) Open System Architecture for Condition-Based Maintenance (OSA-CBM), OSACBM Available

at: http://www.mimosa.org/mimosa-osa-cbm (Accessed: 2 December 2017).

Skaf, Z. and Jennions, I. (2017) Knowledge management system for the IVHM centre. Available at:

https://www.cranfield.ac.uk/research/phd/knowledg e-management-system-for-the-ivhm-centre (Accessed: 24 February 2017).

Yang, E., Matthews, B. and Wilson, M. (2013) 'Enhancing the core scientific metadata model to incorporate derived data', Future Generation Computer Systems, 29(2), pp. 612-623. doi: 10.1016/j.future.2011.08.003. 